\title{
Seroprevalence of parvovirus B19 and its clinical effect among anaemic SCA patients in Northeastern Nigeria
}

\author{
AA Bukar ${ }^{1}$, UAM Abjah ${ }^{1}$, MB Kagu $^{1}$, Al Ladu ${ }^{1}$, SB Zailani ${ }^{2}$, AM Abba ${ }^{1}$, MB Malah $^{1}$, JP \\ Ambe $^{3}$, BA Denue ${ }^{4}$ \\ ${ }^{1}$ Department of Haematology and Blood Transfusion University of Maiduguri Teaching \\ Hospital \\ ${ }^{2}$ Department of Medical Microbiology University of Maiduguri Teaching Hospital \\ ${ }^{3}$ Department of Paediatrics University of Maiduguri Teaching Hospital \\ ${ }^{4}$ Department of Internal Medicine University of Maiduguri Teaching Hospital

\begin{abstract}
\end{abstract}
Sickle cell anaemia (SCA) is a globally widespread genetic disorder affecting $5 \%$ of the world's over 6 billion people. Parvovirus infection and the resulting aplastic crisis is a recognised complication in individuals with SCA. Aplastic crisis increases the need for blood transfusion and its attendant risk of Transfusion Transmissible Infection (TTI). Hence there is a vicious cycle in which Parvovirus B19 causes aplastic crisis which in turn causes increased transfusion need; and transfusion increases risk of transfusion transmissible infection in which parvovirus B19 is included in certain parts of the world. Sickle cell anaemia is associated with foetal death and infection with parvovirus B19 increases the risk to early mortality. The objective of this study was to determine the seroprevalence of parvovirus B19 among SCA and compare with that of controls in the study area. Furthermore clinical and laboratory profile of subjects were analysed to identify possible correlation with parvovirus B19 seropositivity and explore the possibility of involvement of white cell and platelets. A total of 90 subjects comprising 45 consecutive SCA case subjects and 45 age- and sex- matched non SCA controls were studied in a cross sectional comparative study. Ten millilitres of blood was drawn from the antecubital fossa of each subject after obtaining informed consent. The $10 \mathrm{mls}$ of blood was divided into two aliquots, $4.5 \mathrm{mls}$ was added into EDTA anticoagulated bottle and was used for basic complete blood count $(\mathrm{CBC})$, while the remaining $5 \mathrm{mls}$ was added into a plain specimen container allowed to clot and serum obtained to test for anti- parvovirus B19 IgG and $\operatorname{lgM}$ using an immunochromatography based technique specifically BIOCARD ${ }^{\mathrm{TM}}$ Parvo B19 diagnostic test kit. There was male preponderance in the study. The SCA subjects comprised 26 males and 19 females (male to female ratio $=1.4: 1$ ), while the non- SCA controls comprised 25 males and 20 females (male to female ratio 1.3:1).. The analysis of anti- parvovirus B19 IgG antibody revealed a prevalence of $23.3 \%$ among SCA cases with $18.9 \%$ among controls. The haematological profile is not affected by $\lg G$ seropositivity. However pregnancy outcome revealed that the total number of stillbirths is 12 among IgG seropositive SCA cases which is higher than the 6 encountered in IgG seronegative SCA subjects; the difference is statistically significant $(p=0.04)$.

\section{INTRODUCTION}

Sickle cell anaemia (SCA) runs a variable clinical course ranging from mild disease diagnosed incidentally, to crippling severe disease ${ }^{1}$. Patients can be in relative good health termed 'steady state' which may be periodically interrupted by acute exacerbations called 'Crisis' characterised by sudden onset and even fatal outcomes. The Crisis is traditionally classified as Vaso- occlusive, Aplastic,
Sequestration, and Hyperhaemolytic Crises ${ }^{2,3,4}$. The last three are also called anaemic crises.

Parvovirus B19 attracts attention because aplastic crisis in SCA is caused mainly by Parvovirus B19 infection $^{5}$. The anaemia induced by Parvovirus B19 infection is of minor clinical significance in healthy children and adults; however, it becomes critical in those afflicted with haemolytic diseases ${ }^{1,}{ }^{5}$. Parvovirus B19 was first discovered incidentally in 
1975 by Yvonne Cossart and her coworkers while assessing for Hepatitis virus in a serum sample from a blood donor whence they first identified parvoviruslike particles in serum coded "number 19, panel B" hence the name Parvovirus $B 19^{6}$. It belongs to the genus erythrovirus of the family Parvoviridae which are single stranded small DNA viruses. The viral genome codes for three proteins; a non structural protein named NS1 and two structural proteins termed VP1 and VP2. The NS1 protein is cytotoxic to human target cells and is also responsible for packaging viral progenies while VP1 and VP2 are the minor and major components of the viral capsid with VP1 playing a major role in target cell attachment and cell entry ${ }^{7}$. The main cell affected by Parvovirus B19 is the developing erythroblast as the receptor which binds to the virus, identified as $\mathrm{P}$ blood group or Globoside, and is found in abundance on erythroblast and cells of the erythroid lineage ${ }^{8}$. Parvovirus B19 has a profound effect on the erythroid lineage by being cytopathic to it with resulting erythroblastopenia in the bone marrow, giving the erythroid progenitors a characteristic 'megaloblastic' appearance with peripheral reticulocytopenia ${ }^{9}$. There are reports of involvement of not only transient aplastic crisis (TAC) involving the red cells but also the white cell ${ }^{10}$ and thrombocytes ${ }^{11}$. The present study evaluated the haematologic profile of subjects to deduce the effect of Parvovirus B19 seropositivity.

In addition to the haematological effect, intrauterine infections of fetuses in pregnant women do occur resulting in hydrops fetalis and foetal death ${ }^{12}$. Parvovirus B19 has been implicated as a causative agent in fulminant hepatitis even in healthy individuals ${ }^{13}$. Parvovirus B19 can be transmitted through respiratory secretions, transplacentally and by transfusion of blood or blood products ${ }^{14,15}$. The study also tried to explore the relationship between stillbirth, history of transfusion and Parvovirus B19 in the study population.

Antibody response in Parvovirus B19 infection is directed against two capsid proteins namely VP1 and VP2, the majority of virus neutralizing antibodies responsible for life-long protection against reinfections are directed against the VP1-unique region $^{16,}{ }^{117}$. $\lg M_{\text {is }}$ mainly directed against VP2specific epitopes ${ }^{17}$. These $\operatorname{lgM}$ antibodies may be present for a rather short period of two to ten weeks after acute infection ${ }^{16,17}$. IgG-antibodies against the nonstructural protein NS1 are preferentially found in patients who are unable to eliminate the virus and develop persisting viraemia or virus persistence in distinct organs, e.g. synovial fluid, liver, bone marrow $^{16}$.

Two detection methods are currently utilized for the identification of Parvovirus B19 infection, nucleic acid testing techniques and antibody detection methods ${ }^{17}$. The main nucleic acid testing (NAT) technique used for $\mathrm{B} 19$ detection is polymerase chain reaction (PCR) and both qualitative and quantitative PCR strategies exist for the detection of all three B19 genotypes ${ }^{18}$. Apart from total genotype detection, the balance between PCR assay sensitivity and specificity to facilitate detection of acute infection only is important $^{18}$.

The second method for detection of Parvovirus B19 infection is the antibody detection method. And two types are utilized in the clinical setting namely Enzyme- linked immunosorbent assay (ELISA) and immunochromatographic techniques ${ }^{17},{ }^{18}$. The sensitivity of ELISA was compared to nucleic acid technique by Sato et $\mathrm{al}^{19}$ and was found to be less sensitive and specific. However ELISA methods remain a very popular and valid method for the detection of Parvovirus $B 19^{20}$

The search for prompt and type specific method for the detection of Parvovirus B19 infection led to the development and utilization of an immunochromatographic technique ${ }^{21,}{ }^{22}$. The immunochromatographic method in principle resembles ELISA but the enzyme is substituted by chromatographic materials that appear as visible colours on antigen- antibody reaction in the presence of positive Parvovirus B19 infection. The reaction targets a Parvovirus B19 Epitope- type specific VP2 Immunoglobulin G. Kaikkonen et $\mathrm{al}^{22}$ compared the sensitivity and specificity of this method to other EIA methods and found the diagnostic sensitivity to be $98 \%$ and a diagnostic specificity of $94 \%$. In combination with conventional approaches, the epitope-type assays increase greatly the accuracy of Parvovirus B19 diagnosis besides the added advantages of enhancing prompt diagnosis and being less expensive ${ }^{22}$. The study went to utilise the immunochromatographic method to determine the seroprevalence of Parvovirus B19 infection.

\section{METHOD}

This study was carried out at Department of Haematology and Blood Transfusion of University of Maiduguri Teaching Hospital (UMTH) Maiduguri North Eastern Nigeria. Ninety consecutive subjects were recruited and these comprised forty five subjects confirmed to be $\mathrm{HbSS}$ and forty five $\mathrm{HbAA}$ 
subjects as controls. There was male preponderance in the study with the SCA patients comprising 26 males and 19 females (male to female ratio $=1.4: 1$ ) while the non SCA controls comprised of 25 males and 20 females (Male to female ratio= 1.3:1). Nineteen $(42.2 \%)$ of the SCA subjects were less than 15 years of age and twenty six (57.8\%) were greater than or equals to 15 years of age. Among the Controls twenty $(44.4 \%)$ were below 15 years of age while $25(55.6 \%)$ were greater than or equals to 15years of age. After recruitment, Clinical assessment of study subjects were done and included administering a questionnaire containing information on demographic data, number of pregnancy and stillbirths. Subsequently $10 \mathrm{mls}$ of venous blood was obtained from the subjects and control via the antecubital vein. This was separated into two aliquots as follows: $4.5 \mathrm{mls}$ was put into specimen bottle containing Ethylenediamine Tetraacetic acid (EDTA) and the remaining $5 \mathrm{mls}$ into a plain specimen bottle.

The blood sample in the EDTA bottle was used for analysis of haematologic parameters according to method described by Dacie and Lewis ${ }^{23}$. The parameters assessed were packed cell volume/ haematocrit, total white blood cell count, absolute platelet count, Peripheral Blood films were also reviewed to assess the differential leucocytes count and reticulocytes count.

The second aliquot of $5 \mathrm{mls}$ blood in the plain container was allowed to clot and serum was obtained for analysis of Parvovirus B19 antibodies using an immunochromatography based technique specifically BIOCARD ${ }^{\mathrm{TM}}$ Parvo B19 diagnostic test kit. The test was carried out according to the manufacturer's specification as follows: At room temperature, $6.7 \mu \mathrm{L}$ of serum sample was added to $1.0 \mathrm{~mL}$ tube of sample diluent buffer solution to make 1:150 dilution and then mixed properly. Few drops of diluted sample were removed with the aid of pipette. Holding the pipette containing the diluted blood sample vertically, 3 drops of the sample was added onto the round application field (S). After applying the drops, care was taken not to touch and move the test card for 2 minutes. The test is read after 10 minutes. A positive result was indicated as a distinctly visible red line in the test indicator window and a red line in the control indicator window. A negative test shows only the control line.
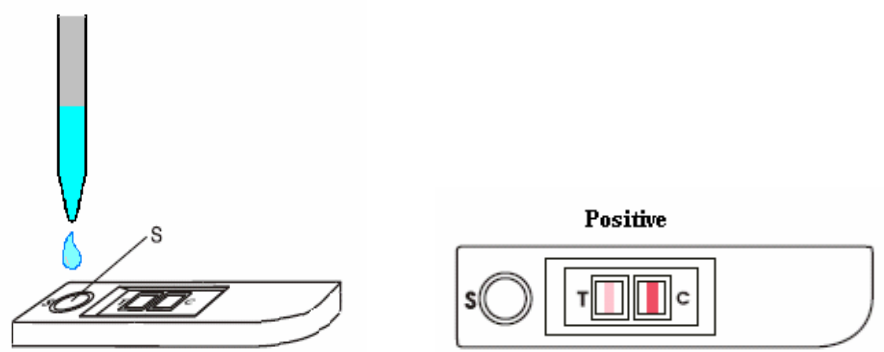

Negative
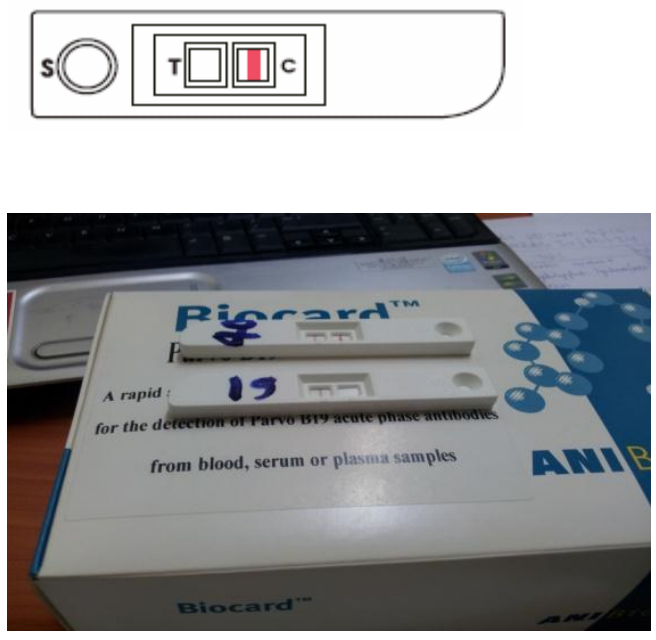

RESULTS

Table 1 shows the seroprevalence of parvovirus B19 IgG antibody. This revealed a prevalence of $23.3 \%$ among SCA cases with $18.9 \%$ among controls. The difference is however not statistically significance $P<0.05$.

Table 1: Seroprevalence parvovirus B19 infection among Study subjects based on IgG seropositivity

\begin{tabular}{|l|c|c|c|}
\hline Characteristics & SCA Cases, $\mathbf{n}(\%)$ & non-SCA Controls & P value \\
\hline $\operatorname{lgG}$ positive & $21(23.3)$ & $21(23.3)$ & 0.393 \\
\hline $\operatorname{lgG}$ positive & $24(26.7)$ & $28(31.1)$ & 0.393 \\
\hline
\end{tabular}


Categories of subjects with IgG seropositivity: Table 2 shows the categories of SCA subjects found to be $\lg$ positive. This revealed that out of the 21 IgG seropositive SCA cases, 8 were of paediatric age while 13 were adults; 11 were males and 10 were females. Thus $61.9 \%$ of seropositive SCA subjects are adults compared to only $38.1 \%$ paediatrics subjects.

\section{Table 2: Categories of subjects with IgG seropositivity}

\begin{tabular}{|l|c|c|}
\hline Category & $\begin{array}{c}\text { IgG positive } \\
(\mathrm{n}=21)\end{array}$ & $\begin{array}{c}\text { IgG negative } \\
(\mathrm{n}=24)\end{array}$ \\
\hline Age Group & $8(38.1 \%)$ & 10 \\
\hline $\begin{array}{l}\text { Paediatrics } \\
(<15 y e a r s ~ o f \\
\text { age })\end{array}$ & $13(61.9 \%)$ & 14 \\
\hline $\begin{array}{l}\text { Adults }(\geq 15 \\
\text { years of age })\end{array}$ & $11(52.4 \%)$ & 15 \\
\hline Gender & $10(46.6 \%)$ & 19 \\
\hline Male & & \\
\hline Female &
\end{tabular}

Table 3 compares the mean haematological variables between parvovirus B19 IgG seropositive and IgG seronegative SCA subjects. This shows the mean PCV among IgG seropositive SCA subjects is $12.1( \pm 2.0) \%$ compared to $12.0( \pm 2.3) \%$ among $\operatorname{lgG}$ seronegative SCA subjects, the difference is not statistically significant $(p=0.260)$. The mean total leukocyte count among parvovirus B19 IgG seropositive and seronegative SCA subjects are $11.8( \pm 3.2) \times 10^{9} / \mathrm{L}$ and $11.0( \pm 3.6) \times 10^{9} / \mathrm{L}$ respectively, the difference is however not statistically significant $(p=0.213)$. The mean reticulocyte index among parvovirus B19 IgG seropositive is $3.0( \pm 2.2)$ $\%$ which is almost equal to the mean reticulocyte index of $3.1( \pm 2.3) \%$ among IgG seronegative SCA subjects, the difference is not statistically significant $(p=0.677)$. Similarly, the mean absolute platelet count among seropositive IgG SCA subjects is $240( \pm 82) x$ $10^{9} / \mathrm{L}$ compared to $275( \pm 65) \times 10^{9} / \mathrm{L}$ among $\operatorname{lgG}$ seronegative SCA subjects, the difference is also not statistically significant $(p=0.120)$. Hence overall there is no effect of IgG seropositivity on haematological profiles of subjects which is not surprising as aplastic crisis is an acute event which should be associated with acute Parvovirus B19 infection as represented by $\lg \mathrm{M}$.

Table 3: Comparison of the mean haematological variables between IgG seropositive and seronegative SCA case subjects

\begin{tabular}{|c|c|c|c|}
\hline Variable & $\begin{array}{c}\text { IgG seropositive, } \mathrm{n}=\mathbf{2 1} \\
\text { Mean ( } \pm \mathrm{SD})\end{array}$ & $\begin{array}{c}\text { IgG seronegative, } \mathrm{n}=24 \\
\text { Mean ( } \pm \mathrm{SD})\end{array}$ & $p$ value \\
\hline Packed cell volume (\%) & $12.1(2.0)$ & $12.0(2.3)$ & 0.266 \\
\hline $\begin{array}{l}\text { Total Leucocyte count } \\
\left(\mathrm{X} 10^{9} / \mathrm{L}\right)\end{array}$ & $11.8(3.2)$ & $11.0(3.6)$ & 0.213 \\
\hline $\begin{array}{ll}\text { Absolute } & \text { Neutrophil } \\
\text { count }\left(\times 10^{9}\right) & \end{array}$ & $7.8(1.0)$ & $7.7(0.6)$ & 0.09 \\
\hline Reticulocyte index (\%) & $3.0(2.2)$ & $3.1(2.3)$ & 0.677 \\
\hline $\begin{array}{l}\text { Absolute platelet count } \\
\left(\mathrm{X} 10^{9} / \mathrm{L}\right)\end{array}$ & $240(82)$ & $275(65)$ & 0.120 \\
\hline
\end{tabular}

Table 4 compares pregnancy and outcome (stillbirths) in Parvovirus B19 IgG seropositive and IgG seronegative SCA subjects. This revealed that 7 $(33 \%)$ of the $21 \lg \mathrm{G}$ seropositive SCA subjects are females within the reproductive age group with all being married whereas $7(29 \%)$ of the $24 \mathrm{lgG}$ seronegative SCA subjects are females of the reproductive age of which 6 are married $(P=0.335)$.
The total number of pregnancies encountered in IgG seropositive SCA subjects is 18 compared to 21 in IgG seronegative SCA subjects $(P=0.01)$. The pregnancy outcome revealed that the total number of stillbirths is 12 among IgG seropositive cases which is higher than the 6 encountered in $\lg$ G seronegative SCA subjects; the difference is statistically significant $(p=0.04)$. 
Am. J. Sci. Ind. Res., 2013, 4(2): 195-200

Table 4: Comparison of pregnancy and outcome (Stillbirths) in IgG seropositive and seronegative SCA subjects

\begin{tabular}{|c|c|c|c|}
\hline Variable & $\begin{array}{c}\text { IgG seropositive, } \mathrm{n}=\mathbf{2 1} \\
\text { Mean }( \pm \mathrm{SD})\end{array}$ & $\begin{array}{c}\text { IgG seronegative, } \mathrm{n}=24 \\
\text { Mean }( \pm \mathrm{SD})\end{array}$ & $p$ value \\
\hline $\begin{array}{l}\text { No of females in } \\
\text { Reproductive age }\end{array}$ & $7(33 \%)$ & $7(29 \%)$ & 0.335 \\
\hline Number Married & $7(33 \%)$ & $6(25 \%)$ & 0.332 \\
\hline Total No. of pregnancies & 18 & 21 & 0.01 \\
\hline Total No. of stillbirths & 12 & 6 & 0.04 \\
\hline
\end{tabular}

\section{DISCUSSION}

Parvovirus B19 infection and its attending consequences is a recognized complication of SCA and other haemolytic anaemias ${ }^{5,6}$. Seroprevalence of the disease can be obtained by antibody detection techniques in which the various methods notably Nucleic acid test ${ }^{18}$ (NAT) using PCR, antibody detection using ELISA techniques ${ }^{21}$. The search for prompt and type specific method for the detection of Parvovirus B19 infection led to the development and adoption of an immunochromatographic technique ${ }^{21}$, 22. Utilizing the immunochromatographic method in this study, the seroprevalence of anti-parvovirus B19 $\lg$ G was found to be $23.3 \%$ among SCA subjects as compared to $18.9 \%$ among control subjects. A study by Abraham et $\mathrm{al}^{23}$ in India found a prevalence of $50 \%$, however in Europe, a study in Serbia ${ }^{24}$ revealed a prevalence of acute parvovirus B19 to be $32 \%$ among subjects and even higher (43\%) among children. Their results were found to be closer to the value obtained in the index study.

The notable effect of Parvovirus B19 infection from previous studies was marked on the developing red cells, but few reports indicated the involvement of white cells ${ }^{10}$ and platelets ${ }^{11}$. This study evaluated the haematological profile of SCA patients with and without IgG seropositivity. It revealed a higher mean total leukocyte count among IgG seropositive than in $\lg$ seronegative SCA subjects, but the difference is not statistically significant $(P=0.213)$. This tallies with earlier reports by Girei et $\mathrm{al}^{25}$ and Alao et $\mathrm{al}^{26}$ who found no significant difference in the total leukocyte count between $\lg G$ seropositive and $\lg G$ seronegative SCA subjects. Furthermore, the index study found the mean absolute platelet count to be lower among IgG seropositive SCA subjects as compared to IgG seronegative SCA subjects; the difference is however not statistically significant $(p=0.120)$. This differs from the finding in the study by Girei et $\mathrm{al}^{25}$ who reported statistically significant difference in mean absolute platelet count between IgG seropositive and IgG seronegative subjects. The disparity seen in the index study might be due to the recruitment of anaemic subjects in the index study. The index study also found a lower mean reticulocytes index among IgG seropositive subjects as compared to $\lg G$ seronegative subjects but this is not statistically significant $(P=0.677)$. The finding of low reticulocytes index is consistent with the finding in aplastic crisis ${ }^{5,26}$. This happens to be a prominent complication of acute parvovirus B19 infection among individuals with $\mathrm{SCA}^{26}$.

In addition to the haematological effect intrauterine infection of fetuses in pregnant women occur resulting in hydrops fetalis and fetal death ${ }^{12}$. We noted a statistically significant relationship between IgG seropositivity and stillbirths $(p=0.04)$. These tallies with the report by Heegard et $\mathrm{al}^{10}$ which implicated a vertical transmission of parvovirus B19 and qualifies its role in causation of abortion and stillbirths.

\section{CONCLUSION}

The prevalence of Parvovirus B19 in our community is noted to be $23.3 \%$ and $18.9 \%$ among SCA and non SCA subjects respectively. There are no strong association between the haematologic parameters and Parvovirus B19 seropositivity. However we found an association of the viraemia with foetal outcome.

In the light of the above, we recommend that the screening for Parvovirus B19 in SCA with poor foetal outcome be undertaken. And likewise the screening of blood and blood products for Parvovirus B19 be established for SCA patients who are pregnant. 


\section{REFERENCES}

1. Weatherall D J. Genetic disorders of Haemoglobin. In: Hoffbrand AV, Lewis SM, Tuddenham EGD (Eds). Postgraduate Haematology $4^{\text {th }}$ edition. Great Britain. Butterworth- Heinemann, 1999: 91- 119.

2. Olabode JO, Shokunbi WA. Types of crises in sickle cell disease patients presenting at the haematology day care unit (HDCU), university college hospital (UCH), Ibadan. West Afr J Med 2006 Oct- Dec 2; 25(4): 284- 8.

3. Beutler E. The Sickle Cell Diseases and related problems. In: Williams JW, Beutler E, Erslev AJ, Lichtman M (Eds). Haematology $4^{\text {th }}$ edition. New York: McGraw- Hill, 1990: 613- 644.

4. Juwah A, Nlemadin E, Kaine W. Types of anaemic crises in paediatric patients with sickle cell anaemia seen in Enugu, Nigeria. Arch Dis Child. 2004 June; 89(6): 572- 576.

5. Chisaka H, Morita E, Yaegashi N, Suganama K. Parvovirus B19 and the pathogenesis of anaemia. Rev Med Virol. 2003 Nov- Dec; 13 (6):347-59.

6. Pattison JR: The discovery of human parvovirus. In Parvoviruses and Human Disease. Edited by Pattison JR. Boca Raton: CRC Press, Inc.; 1988:1-4.

7. Cotmore SF, McKie VC, Anderson LJ, et al.: Identification of the major structural and nonstructural proteins encoded by human parvovirus B19 and mapping of their genes by procaryotic expression of isolated genomic fragments. J Virol 1986, 60:548-557

8. Brown KE, Anderson SM, Young NS. Erythrocyte $\mathrm{P}$ antigen: cellular receptor for B19 parvovirus. Science 1993; 262:114-117.

9. Pattison, J.R., Jones, S.E., Hodgson, J., Davis, L.R., White, J.M., Stroud, C.E. \& Murtaza, L. (1981) Parvovirus infections and hypoplastic crisis in sickle-cell anaemia. Lancet 1, 664-665.

10. Doran HM, Teall AJ. Neutropenia accompanying erythroid aplasia in human parvovirus infection. $\mathrm{Br}$ J Haematol 1988; 69:287-288.

11. Inoue S, Kinra NK, Mukkamala SR et al. Parvovirus B-19 infection: aplastic crisis, erythema infectiosum and idiopathic thrombocytopenic purpura. Pediatr Infect Dis J 1991; 10:251-253.

12. Brown, T., Anand, A., Ritchie, L.D., Clewley, J.P. \& Reid, T.M (1984) Intrauterine parvovirus infection associated with hydrops fetalis. Lancet, 2, 1033-1034.

13. Langnas, A.N., Markin, R.S., Cattral, M.S. \& Naides, S.J. (1995) Parvovirus B19 as a possible causative agent of fulminant liver failure and associated aplastic anemia. Hepatology, 22, $1661-1665$

14. Zanella A, Rossi F, Cesana C et al. TransfusionTransmitted human parvovirus B19 infection in a thalassemic patient. Transfusion 1995; 35: 769.
15. Prowse, C., Ludlam, C.A. \& Yap, P.L. (1997) Human parvovirus B19 and blood products. Vox Sanguinis, 72, 1-10.

16. Modrow S, Dorsch S. Antibody responses in parvovirus B19 infected patients. Pathol Biol (Paris). 2002 Jun; 50(5):326-31.

17. Corcoran A, Doyle S. Advances in the biology, diagnosis and host- pathogen interactions of Parvovirus B19. Journal of Medical Microbiology 2004; 53: 459- 475

18. Daly P, Corcoran A, Mahon B.P., and Doyle S. High sensitivity PCR detection of parvovirus B19 in plasma. J Clin Microbiol 2002; 40(6), 19581962.

19. Sato K, Matsuda E, Kamisango K, Iwasaki H, Matsubara S, Matsunaga Y. Development of a hypersensitive detection method for human Parvovirus B19 DNA. J Clin Microbiol 2000; 38(3): $1241-1243$.

20. Doyle S. The detection of Parvoviruses (Chapter 13). In: Stephenson JR, Warnes A (eds). Diagnostic Virology Protocols, Methods in Molecular Biology. New York. Springer- Science 2011; 665: 213- 231.

21. Wong S, Brown KE. Development of an improved method of detection of infections by Parvovirus B19. J Clin Virol 2006; 35: 407- 413.

22. Kaikkonen L, Soderlund- Venermo M, Brunstein J, Schou O, Jensen JP, et al. Diagnosis of Human Parvovirus B19 infections by Epitope- type specific VP2 IgG. J Med Virol 2001; 64: 360- 365.

23. Abraham M, Rudraraju $R$, Kannangai $R$ et al. $A$ pilot study on the seroprevalence of parvovirus B19 infection. Indian J med res. 2002 Apr; 115: Pp139-143.

24. Milosevic V, Jerant-Patic V, Hrnjakovic-Cvjetkovic I, Vukmanovic-Papuga M, Radovanov-Tadic J, Kovacevic $\mathrm{G}$. The frequency of human parvovirus B19 infections in Vojvodina. Medicinski pregled. 2007; 60(11-12): 575-579.

25. Girei AI, Alao OO, Joseph DE, Damulak DO, Orkuma J, Banwat EB. Haematological profile of sickle cell anaemia in children with human parvovirus B19 infection in Jos, North Central Nigeria. Journal of Clinical Medicine and Research September 2010; 2(9) Pp 152-155.

26. Alao OO, Girei Al, Joseph DE, Banwat EB, Araoye MO, Orkuma J, Jombo GTA. Effect of socioeconomic demographic variables on Antiparvovirus B19 Antibody Seropositivity among Children with SCA in Jos, North Central Nigeria. The Internet Journal of Epidemiology. 2010; 8(2).

27. Charney E, Miller G. Reticulocytopenia in sickle cell disease: Aplastic episodes in the course of sickle cell disease in children. Am $\mathrm{J}$ Dis child. 1964; 107: 450. 